Abstracta Iranica Abstracta Iranica

Revue bibliographique pour le domaine irano-aryen

Volume 32-33 | 2013

Comptes rendus des publications de 2009-2010

\title{
Iago Gocheleishvili. Introducing Georgian Sources for the Historiography of the Iranian Constitutional Revolution (1905-1911)
}

\section{Denis Hermann}

\section{(2) OpenEdition}

1 Journals

\section{Édition électronique}

URL : http://journals.openedition.org/abstractairanica/40767

DOI : 10.4000/abstractairanica.40767

ISSN : 1961-960X

Éditeur :

CNRS (UMR 7528 Mondes iraniens et indiens), Éditions de l'IFRI

\section{Édition imprimée}

Date de publication : 1 décembre 2013

ISSN : 0240-8910

Référence électronique

Denis Hermann, « lago Gocheleishvili. Introducing Georgian Sources for the Historiography of the Iranian Constitutional Revolution (1905-1911) », Abstracta Iranica [En ligne], Volume 32-33 | 2013, document 288, mis en ligne le 01 juillet 2016, consulté le 26 septembre 2020. URL : http:// journals.openedition.org/abstractairanica/40767 ; DOI : https://doi.org/10.4000/abstractairanica 40767

Ce document a été généré automatiquement le 26 septembre 2020.

Tous droits réservés 


\title{
Iago Gocheleishvili. Introducing Georgian Sources for the Historiography of the Iranian Constitutional Revolution (1905-1911)
}

\author{
Denis Hermann
}

\section{RÉFÉRENCE}

Iago Gocheleishvili. «Introducing Georgian Sources for the Historiography of the Iranian Constitutional Revolution (1905-1911) ", in : Houchang E. Chehabi \& Vanessa Martin, eds., The Iranian Constitutional Revolution. Londres, I.B. Tauris, 2010, p. 45-66.

L'article de Iago Gocheleishvili est certainement le plus original du chapitre consacré à l'historiographie du mouvement constitutionnaliste dans ce beau volume. Ce dernier présente en détail les sources géorgiennes concernant le mouvement constitutionnaliste. En dépit de leur grand nombre et de leur intérêt, celles-ci restent largement méconnues des chercheurs. Il s'agit essentiellement de mémoires de Géorgiens engagés dans des groupes pro-constitutionnalistes en Iran - le plus souvent armés -, de courts rapports ou de lettres que ces militants envoyaient en Géorgie et qui étaient souvent publiés dans différents journaux, d'articles de journaux consacrés aux développement du mouvement en Iran et enfin des archives de renseignement. Ces militants géorgiens étaient particulièrement actifs en Azerbaïdjan et au Gilan. Il semble que ces derniers jouèrent un rôle central dans la résistance de Tabriz aux forces royales après la fermeture du parlement, notamment en fournissant denrées alimentaires, armes et munitions. Les volontaires géorgiens, le plus souvent des descendants de migrants iraniens, étaient par ailleurs des soldats bien entraînés. Pour autant, ils insistaient dans leurs mémoires et leurs lettres sur leurs statuts de caucasiens, et même 
d'« internationalistes " apportant une "aide fraternelle » à une nation souhaitant au même titre qu'en Russie s'affranchir d'un régime tyrannique. Ces documents révèlent aussi les oppositions idéologiques divisant ces révolutionnaires, principalement entre bolchéviques et menchéviques alors majoritaires en Géorgie. Ils démontrent également que les Géorgiens et les Transcaucasiens défendaient généralement des positions politiques plus radicales que les Iraniens ou les Arméniens, particulièrement scandalisés par le sort des classes inférieures.

\section{AUTEURS}

\section{DENIS HERMANN}

CNRS, Mondes iranien et indien, Paris 